\title{
Decomposition and particle release of a carbon nanotube/ epoxy nanocomposite at elevated temperatures
}

\author{
Lukas Schlagenhauf • Yu-Ying Kuo • \\ Yeon Kyoung Bahk · Frank Nüesch · Jing Wang
}

Received: 6 June 2015/ Accepted: 4 November 2015

(C) Springer Science+Business Media Dordrecht 2015

\begin{abstract}
Carbon nanotubes (CNTs) as fillers in nanocomposites have attracted significant attention, and one of the applications is to use the CNTs as flame retardants. For such nanocomposites, possible release of CNTs at elevated temperatures after decomposition of the polymer matrix poses potential health threats. We investigated the airborne particle release from a decomposing multi-walled carbon nanotube (MWCNT)/epoxy nanocomposite in order to measure a possible release of MWCNTs. An experimental setup was established that allows decomposing the samples in a furnace by exposure to increasing temperatures at a constant heating rate and under ambient air or nitrogen atmosphere. The particle analysis was performed by aerosol measurement devices and by transmission electron microscopy
\end{abstract}

L. Schlagenhauf · F. Nüesch

Laboratory for Functional Polymers, Empa - Swiss

Federal Laboratories for Materials Science and

Technology, Überlandstrasse 129, 8600 Dübendorf,

Switzerland

L. Schlagenhauf · Y.-Y. Kuo · Y. K. Bahk · J. Wang ( $₫)$ Laboratory for Advanced Analytical Technologies, Empa - Swiss Federal Laboratories for Materials Science and Technology, Überlandstrasse 129, 8600 Dübendorf, Switzerland

e-mail: Jing.Wang@ifu.baug.ethz.ch

L. Schlagenhauf · Y.-Y. Kuo · Y. K. Bahk · J. Wang Institute of Environmental Engineering, ETH Zurich,

Stefano-Franscini-Platz 3, 8093 Zurich, Switzerland
(TEM) of collected particles. Further, by the application of a thermal denuder, it was also possible to measure non-volatile particles only. Characterization of the tested samples and the decomposition kinetics were determined by the usage of thermogravimetric analysis (TGA). The particle release of different samples was investigated, of a neat epoxy, nanocomposites with 0.1 and $1 \mathrm{wt} \%$ MWCNTs, and nanocomposites with functionalized MWCNTs. The results showed that the added MWCNTs had little effect on the decomposition kinetics of the investigated samples, but the weight of the remaining residues after decomposition was influenced significantly. The measurements with decomposition in different atmospheres showed a release of a higher number of particles at temperatures below $300{ }^{\circ} \mathrm{C}$ when air was used. Analysis of collected particles by TEM revealed that no detectable amount of MWCNTs was released, but micrometer-sized fibrous particles were collected.

Keywords Nanocomposite Carbon nanotubes ·

Thermal decomposition - Particle release .

Environmental and health effects - Exposure

\section{Introduction}

Composite materials with carbon nanotubes (CNTs) as filler materials have superior properties compared to the neat matrix material. The CNTs can improve the mechanical properties (Hollertz et al. 2011) and add 
new features like electrical (Bai and Allaoui 2003) and thermal conductivity (Huang et al. 2005). Recently, the common brominated flame retardants, e.g., the persistent organic pollutant (POP) hexabromocyclododecane (HBCD), were banned (Covaci et al. 2006; Willis 2012). Therefore, new classes of fire retardants, e.g., CNTs, are needed. During the past decade, the ability of CNTs as fire retardants for polymers was investigated in a number of studies (Kashiwagi et al. 2002, 2004, 2005a, b; Schartel et al. 2005; Zammarano et al. 2008; Verdejo et al. 2008; Kashiwagi et al. 2008; Kim et al. 2009; Fu et al. 2010; Nyden et al. 2010; Uddin et al. 2011; Dittrich et al. 2013).

When a polymer is heated to a sufficiently high temperature, the polymer chains start to degrade into small and volatile molecules, which can feed a flame and by heat radiation thereof, and new volatiles are generated. This process is called the combustion cycle of organic polymers (Mouritz and Gibson 2006). When an epoxy resin is exposed to high temperatures, the decomposition occurs mainly through chain scission reactions, mainly at the $\mathrm{C}-\mathrm{N}$ bonds and at hydroxyl groups. About $90 \%$ of the polymer weight is lost during the decomposition, and the released gas consists of almost 100 different compounds (Vogt $1985)$ and soot particles. The remaining residues are highly porous and stable until $550{ }^{\circ} \mathrm{C}$, at higher temperatures, and in the presence of oxygen they will oxidize.

When incorporated in polymers, CNTs have different influences on the composite combustion properties. The time to ignition (TTI) of a fire is crucial for a material, as it shows how long it can withstand a fire breakout, a key property that is tested in many standards (e.g. ISO 3795-1989). Depending on the polymer matrix, the TTI of fire is lowered by the CNTs (Kashiwagi et al. 2002; Dittrich et al. 2013) or it remains unaffected (Rahatekar et al. 2010). Other important fire properties are the heat release rate (HRR), described by the average heat release rate (AHRR) and the peak heat release rate (PHRR). The HRR is the most important fire property because it is a good indicator of the fire hazard (Babrauskas and Peacock 1992). CNTs have different influences on the two HRR properties, while they can increase the AHRR (Fu et al. 2010), and they decrease drastically the PHRR (Fu et al. 2010; Rahatekar et al. 2010; Dittrich et al. 2013). The lower PHRR can be explained by the formation of a CNT layer on the top of the surface that acts as a diffusion barrier for the released volatiles (Kashiwagi et al. 2002). Other possible impacts on the fire properties are an increased amount of residues due to the CNTs (Dittrich et al. 2013) and the reduction of smoke (Wu et al. 2010).

The incorporation of CNTs can change the decomposition behavior of polymers, caused by a heat source and no local fire. The activation energy of the decomposition, regardless of which degradation process takes place, can be calculated by the usage of Ozawa-Flynn-Wall (OFW) method (Ozawa 1965) where the mass changes are measured by thermogravimetric analysis (TGA) at different heating rates. For many tested polymer/CNT nanocomposites, an increase of the decomposition activation energy, accompanied with an increase of the residue mass was measured (Seo and Park 2004; Lu et al. 2009; Ribeiro et al. 2012; Shariati et al. 2012). For epoxy, opposite to other systems a decrease of the activation energy was reported (Ciecierska et al. 2013).

Because of the toxic and biopersistent nature of CNTs, concerns have been raised that CNT composites can pose a risk to producers and consumers if the CNTs are released into the environment (Kaiser et al. 2011; Wang et al. 2011; Erdely et al. 2013; Du et al. 2013; Nowack et al. 2013). An accidental fire of a $\mathrm{CNT} /$ polymer nanocomposite can be the source of released CNTs not only due to combustion, but also due to thermo degradation from parts that are exposed to heat without a flame. Further, when polymer wastes are pyrolized (Pinto et al. 1999), a possible release of CNTs has to be investigated in order to assure the safety of the workers. When CNTs are released from a burning part, they may pass the flame and are exposed to temperatures above $830{ }^{\circ} \mathrm{C}$ (Mouritz and Gibson 2006) where they degrade. Close to fire sources, the composite surface can be exposed to heat and thus decompose without the generation of a flame. CNTs released in this regime may not pass the flames and can pose a risk when inhaled. This scenario was already simulated by Bouillard et al. (2013) for a polymer nanocomposite with the thermoplastic acrylonitrile butadiene styrene (ABS) as a matrix material and with $3 \mathrm{wt} \%$ of CNTs. A release of free-standing CNTs was detected for this nanocomposite.

When a polymer/CNT nanocomposite is burned in a fire, the residues consist of a large number of accumulated and partially oxidized CNTs (Kashiwagi 
et al. 2002). Those CNTs can be aerosolized by mechanical impact (Nyden et al. 2010) and also pose a danger.

In this study, we performed for the first time a nonisothermal decomposition experiment with a thermoset polymer nanocomposite in order to investigate the possible release of CNTs when the material is exposed to elevated temperatures. The samples are composed of multi-walled carbon nanotubes (MWCNTs) as a filler material and epoxy as a matrix material. They either contained no MWCNTs, untreated MWCNTs at two different concentrations ( 0.1 and $1 \mathrm{wt} \%)$, or two kinds of functionalized MWCNTs, either with carboxylic $(\mathrm{COOH}-$ MWCNTs) or amino $\left(\mathrm{NH}_{2}-\mathrm{MWCNTs}\right)$ side groups. The decomposition was performed either in air or under nitrogen, and the emitted particles were either measured as released or post-treated with a thermal denuder. The particles were characterized by number, size, and mass. Further, electron microscopy was used to detect if free-standing MWCNTs were released into the air and to investigate if the MWCNTs did accumulate on the residue surface.

\section{Materials and methods}

\section{MWCNT functionalization}

MWCNTs (Baytubes, C150p, length 1-10 $\mu \mathrm{m}$, outer mean diameter $13-16 \mathrm{~nm}$ ) were supplied by Bayer Material Science AG, Germany. For the functionalization with carboxylic groups, $1 \mathrm{~g}$ of MWCNTs were refluxed in $700 \mathrm{ml} 9 \mathrm{M}$ nitric acid (ACS reagent, Sigma-Aldrich) at $120{ }^{\circ} \mathrm{C}$ for $24 \mathrm{~h}$ and then washed with distilled water several times until neutralization (Chatterjee et al. 2012). The obtained $\mathrm{COOH}-$ MWCNTs were dried under vacuum at $60{ }^{\circ} \mathrm{C}$.

The functionalization of the MWCNTs with amino groups was carried out with the addition of ethylenediamine (EDA) to carboxylic side groups by Steglich esterification (Neises and Steglich 1978) according to Ma et al. (2010a) and Qu and Wang (2012). $1 \mathrm{~g}$ of $\mathrm{COOH}-\mathrm{MWCNT}$ was refluxed at $120^{\circ} \mathrm{C}$ for $24 \mathrm{~h}$ in $150 \mathrm{~g}$ of ethylenediamine (ReagentPlus, SigmaAldrich), $25 \mathrm{~g}$ of the coupling agent dicyclohexylcarbodiimide (DCC) (D80002, Sigma-Aldrich), and $1.5 \mathrm{~g}$ of the catalyst 4-(dimethylamino)-pyridine (DMAP) (ReagentPlus, Sigma-Aldrich). The $\mathrm{NH}_{2}-\mathrm{MWCNTs}$ were then rinsed with distilled water several times and further dried under vacuum at $60{ }^{\circ} \mathrm{C}$.

Sample preparation

The used epoxy resin was Araldite GY 250 (Huntsman, USA), which is based on bisphenol A. The curing agent was the polyetheramine Jeffamine D-230 (Huntsman, USA) and the used resin/hardener ratio was $100: 32.0 .1$ or $1 \mathrm{wt} \%$ of MWCNTs were added to the epoxy resin, dispersed for $30 \mathrm{~min}$ by ultrasonication, and further dispersed by three-roll milling (SDY200, Bühler AG, Switzerland) at $30{ }^{\circ} \mathrm{C}$ and at a gap pressure of $1 \mathrm{MPa}$. The milling process was applied three times. After mixing with the curing agent and molding, the composite was cured at $80{ }^{\circ} \mathrm{C}$ for $12 \mathrm{~h}$, followed by post curing at $120{ }^{\circ} \mathrm{C}$ for $4 \mathrm{~h}$. We only used epoxy composites with low MWCNT concentrations because Hollertz et al. (2011) showed the mechanical properties were significantly improved when the added MWCNT concentration was less than $1 \mathrm{wt} \%$. Further increase of the MWCNT concentration only marginally improved the properties if at all. It was also observed that strong agglomeration occurred at CNT contents higher than $5 \mathrm{wt} \%$ and concomitantly the mechanical properties degraded. Therefore, we used the optimal concentration around one percent. Such CNT filler concentrations are also common in commercial products (e.g., ZNT-boost, Zyvex) and for research (Ma et al. 2010b; Nguyen et al 2011; Ging et al. 2014).

\section{Decomposition kinetics by thermogravimetry}

The decomposition kinetics was determined by usage of the OFW method according to the ASTM standard E1641-13. For each sample, approx. $10 \mu \mathrm{g}$ of sample mass was analyzed by thermogravimetric analysis (TGA) (TGA 7, Perkin Elmer) with different heating rates, i.e., 1, 2, 5, and $10 \mathrm{~K} / \mathrm{min}$. The analysis was carried out under nitrogen in order to avoid reactions between the sample and oxygen. For normalization of the heating curves, the mass at $250{ }^{\circ} \mathrm{C}$ was defined as $100 \%$ and the activation energies were calculated for conversions between 5 and $70 \mathrm{wt} \%$.

For a lifetime prediction of the samples, i.e., the sample degradation at elevated temperatures without mechanical impact, weathering, or accidental exposure to heat above the decomposition temperature, the 
ASTM standard E1877-11 was used. The critical temperatures for failure, defined at $5 \%$ weight loss, were determined for lifetimes between 1 day and 5 years.

Experimental set-up for the decomposition experiments

A schematic of the experimental set-up for the decomposition experiments is shown in Fig. 1. Approximately $10 \mathrm{mg}$ of sample mass was cut off from a large nanocomposite sample, put in a ceramic boat, and inserted into a tubular muffle furnace (CTF, Carbolite, Germany). Both ends of the furnace tube were fitted to custom-made connectors that allow connecting tubes for air supply and collection of the released particles.

The tube was flushed either by air, cleaned with a HEPA filter, or by nitrogen from a gas bottle. The inlet flow rate was controlled by a mass flow controller and was set to $1 \mathrm{l} / \mathrm{min}$ for all experiments. Directly after the furnace outlet, the gas was introduced into a box of $10 \mathrm{l}$ volume where it was mixed with cleaned air. This dilution process was necessary to avoid condensation of volatile organic molecules on transport lines and instruments, and to cool down the gas in order to reduce the line loss of particles due to thermophoresis and Brownian motion. The dilution air was cleaned with a HEPA filter and injected at a flow rate of $39 \mathrm{l} /$ min resulting in an average residence time of $15 \mathrm{~s}$ for the furnace exhaust gas. After the dilution box, part of the gas passed a home-built thermal denuder or bypassing tubing and was analyzed by a scanning mobility particle sizer (SMPS) consisting of a differential mobility analyzer (DMA) equipped with a long DMA column (Model 3080, TSI, USA) and a condensation particle counter (CPC) (Model 3775,
TSI, USA). The rest was transferred to the exhaust. The thermal denuder was used to distinguish released organic volatile particles from soot (Burtscher et al. 2001). It was heated to $380{ }^{\circ} \mathrm{C}$ and, in addition to the volatilization tube, it also consisted of a catalyst that disintegrated the organic volatiles. From the measured data, the obtained particle and mass concentrations were adopted directly from the measurement software without further processing (assumed particle density $1 \mathrm{~g} / \mathrm{cm}^{3}$ ). The measured particle modes were obtained by fitting with a lognormal distribution (Schlagenhauf et al. 2012). Parallel to the SMPS, a nanometer aerosol sampler (NAS) (Model 3089, TSI, USA) was used to collect particles on TEM grids. The SMPS was run at a flow rate of $0.3 \mathrm{l} / \mathrm{min}$ and the NAS at $0.5 \mathrm{l} / \mathrm{min}$. To measure also the size distribution of droplets, consisting of condensed volatiles, it was possible to bypass the denuder by an additional line.

For particle imaging, the collected particles were investigated by TEM (CM30, Philipps, Netherlands). The residues of the decomposition process were imaged by SEM (Nova NanoSEM 230, FEI, USA).

\section{Statistical analysis}

The significance of difference between different datasets was measured with $F$ tests by the usage of one-way analysis of variance (ANOVA) (OriginPro 8, OriginLab Corporation, USA).

\section{Results}

\section{Decomposition kinetics}

The decomposition kinetics of the samples, investigated by TGA, are shown in Fig. 2. The mass of the

Fig. 1 Scheme of the experimental set-up

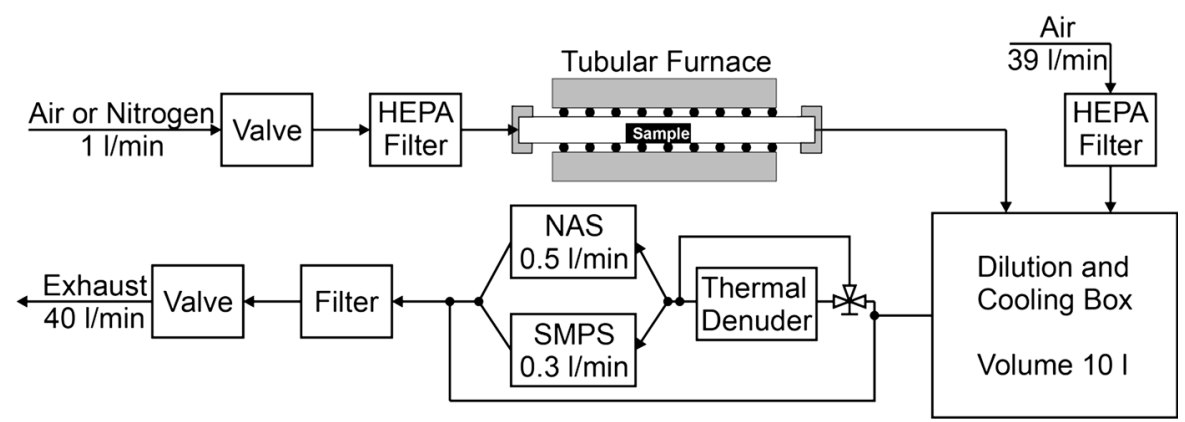


residues at the end of each measurement $\left(T=690{ }^{\circ} \mathrm{C}\right)$ is shown in Fig. 2a. It is observed that two parameters influenced the weight of the residues, the addition of MWCNTs and the heating rate of the measurement. The remaining mass of the neat epoxy samples is almost constant for all experiments. For the nanocomposites, a higher mass compared to the neat epoxy was measured for low heating rates and a lower mass for high heating rates. The average of all composites decreased from $10.8 \pm 0.5 \mathrm{wt} \%$ at $1 \mathrm{~K} / \mathrm{min}$ to $7.9 \pm 0.8 \mathrm{wt} \%$ at $10 \mathrm{~K} / \mathrm{min}(p<0.001)$.

The activation energies for different weight conversions for all samples are shown in Fig. 2b. Until the conversion of the sample mass of $30 \%$, the activation energy of the neat epoxy was slightly larger than for the composites $(p<0.04)$. At conversions above $30 \%$, no differences between the samples can be clearly identified and, between 60 and $70 \%$, a change of the degradation mechanism is observable with the consequence that the activation energies and the experiment uncertainty increased evidently.

The lifetime prediction of the samples according to ASTM 1877 for a conversion of $5 \%$ is shown in Fig. 2c. The neat epoxy showed the longest lifetime and would last at $200{ }^{\circ} \mathrm{C}$ approximately 2.3 times longer than the $0.1 \mathrm{wt} \%$ MWCNT sample with the shortest lifetime, which correlates directly with the calculated activation energy.

Emission characterization-influence of the atmosphere and the thermal denuder

Figure 3 shows the influence of the atmosphere and the thermal denuder on the released aerosol from the neat epoxy sample. The presence of oxygen in the atmosphere had a visible influence on the total particle number concentration, shown in Fig. 3a. Under nitrogen, the particle concentration increased continuously during the heating until the maximum conversion rate at approx. $360{ }^{\circ} \mathrm{C}$. Then it decreased and at temperatures above $425{ }^{\circ} \mathrm{C}$ a constant release of particles was measured. Under air, more particles were released at low temperatures compared to the sample in inert atmosphere. At approximately $300{ }^{\circ} \mathrm{C}$, a first maximum was reached, followed by a brief decrease of the particle concentration. Afterwards, the measured particle release showed the same curve progression as for the sample under nitrogen.

Further, in Fig. 3a, the influence of the thermal denuder on the particle concentration under the two different atmospheres is shown. For both measurements, a background particle concentration of (a)

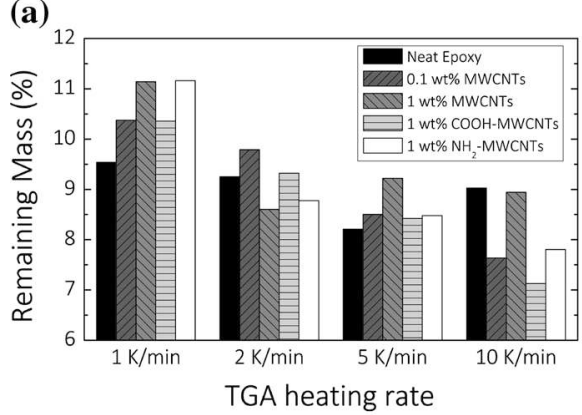

(b)

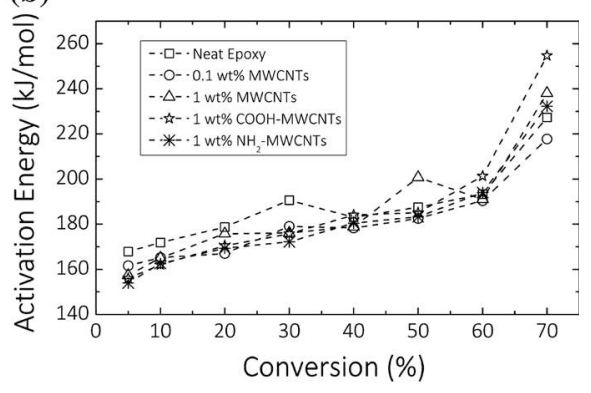

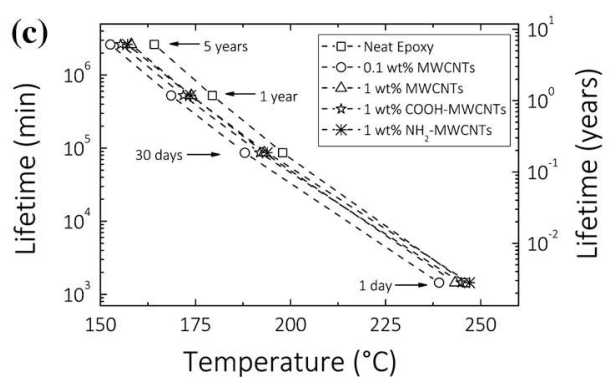

Fig. 2 Results of the TGA measurements. a remaining mass of the residues; $\mathbf{b}$ activation energies of the samples for the different conversions; and $\mathbf{c}$ lifetime predictions for the samples. The lines are inserted to guide the eye 
Fig. 3 Decomposition of a neat epoxy sample during the non-isothermal experiment under the four possible set-up configurations: under air or under nitrogen, and without or with an applied thermal denuder. The released aerosol was characterized by the particle number concentration (a), the particle mode (b), and the particle mass concentration (c) (a)

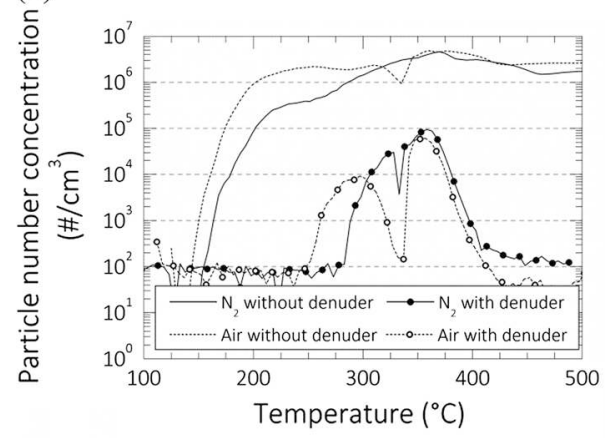

(b)

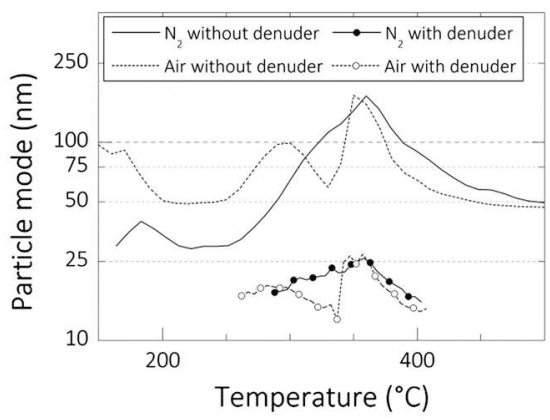

(c)

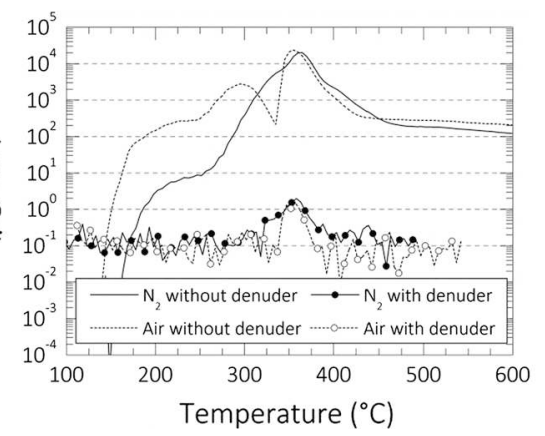

approximately 100 particles $/ \mathrm{cm}^{3}$ was measured. Below $250{ }^{\circ} \mathrm{C}$ and above $400{ }^{\circ} \mathrm{C}$, no particle release can be distinguished from the background. Under nitrogen, the particle concentration started to increase at $300{ }^{\circ} \mathrm{C}$ and increased up to a maximum value of $10^{5} \mathrm{~cm}^{-1}$ at $360{ }^{\circ} \mathrm{C}$; this was approximately $2 \%$ of the particles measured when no denuder was applied.

Under oxygen, the measured particle concentration with the applied thermal denuder started to increase at a lower temperature than under nitrogen. Similar to the measured values when no thermal denuder was applied, also this measurement showed two maxima at the similar temperatures. Above $360{ }^{\circ} \mathrm{C}$, the measurement showed the same behavior as the sample that was decomposed under nitrogen.

The influences of the atmosphere and the denuder on the mode of the particle size distribution are shown in Fig. 3b. For the different atmospheres, it is visible that the particle modes correlated with the particle concentrations. The largest particles were measured during the period when the highest particle concentrations were observed. Above $400{ }^{\circ} \mathrm{C}$, the particle modes decreased to the same dimensions as in the beginning of the experiment, even though the particle concentration remained at a high level. When a thermal denuder was applied in the experimental set- up, the largest measured particle mode was only $25 \mathrm{~nm}$. Below $300{ }^{\circ} \mathrm{C}$ and above $400{ }^{\circ} \mathrm{C}$, only a few particles passed the denuder and thus the mode of the size distribution could not be determined.

The measured particle mass concentrations are shown in Fig. 3c. In accordance with the measured particle number concentrations, the oxygen in the air caused a higher release compared to the nitrogen atmosphere in the range below $300{ }^{\circ} \mathrm{C}$, and approximately at $340{ }^{\circ} \mathrm{C}$ a local minimum is visible. The mass release during the first local maximum was approximately one order of magnitude lower compared to the maximum conversion rate. Above $400{ }^{\circ} \mathrm{C}$, the oxygen had no influence on the mass concentration. When the denuder was added, only little mass was measured at the maximum conversion temperature. The non-volatile soot particles accounted only for $0.01 \%$ of the released particle mass. The soot particle release during the decomposition in air below $300{ }^{\circ} \mathrm{C}$ cannot be distinguished from the background.

Emission characterization-influence of untreated and functionalized MWCNTs

The influences of the added MWCNTs on the particle release during the decomposition are shown in Fig. 4. 
The measurements under nitrogen and without an applied thermal denuder are shown in Fig. 4a, b. Compared to the neat epoxy, the two samples with functionalized MWCNTs showed a release of fewer particles at temperatures below $200{ }^{\circ} \mathrm{C}$. At higher temperatures, this difference vanished. No substantial differences were measured for the particle mass concentrations, and only the temperatures of the maximum particle release rate were different for each sample, but no specific trend is observed. At the applied heating rate of $5 \mathrm{~K} / \mathrm{min}$, the MWCNTs had no influence on the total mass loss, which is in agreement with the results of the TGA measurements with a heating rate of $5 \mathrm{~K} / \mathrm{min}$ in Fig. 2a.

Figure $4 \mathrm{c}$ and $\mathrm{d}$ show the particle release properties for the composites compared to the neat epoxy under nitrogen atmosphere and with the thermal denuder. No substantial differences were measured between the neat epoxy sample and the samples with untreated MWCNTs.

The particle release properties for the composites compared to the neat epoxy under air and with the thermal denuder are presented in Fig. 4e, f. As already shown in Fig. 3a, the measurement of the solid particles showed two distinct number concentration maxima during the heating process. At the maximum conversion rate near $350{ }^{\circ} \mathrm{C}$, both the particle number (Fig. 4e) and mass (Fig. 4f) concentrations showed higher values for the $0.1 \mathrm{wt} \%$ MWCNT composite than for the neat epoxy sample. The higher particle release of the $0.1 \mathrm{wt} \%$ composite was likely related to its lower activation energy (Fig. 2b).
Fig. 4 Particle release during decomposition of the nanocomposites, compared to the neat epoxy sample. The measured particle number concentrations and the particle mass concentrations are shown for different experimental set-ups: a, b under nitrogen atmosphere without posttreatment; c, $\mathbf{d}$ under nitrogen atmosphere with post-treatment by the thermal denuder; and $\mathbf{e}$, f under air with posttreatment by the thermal denuder
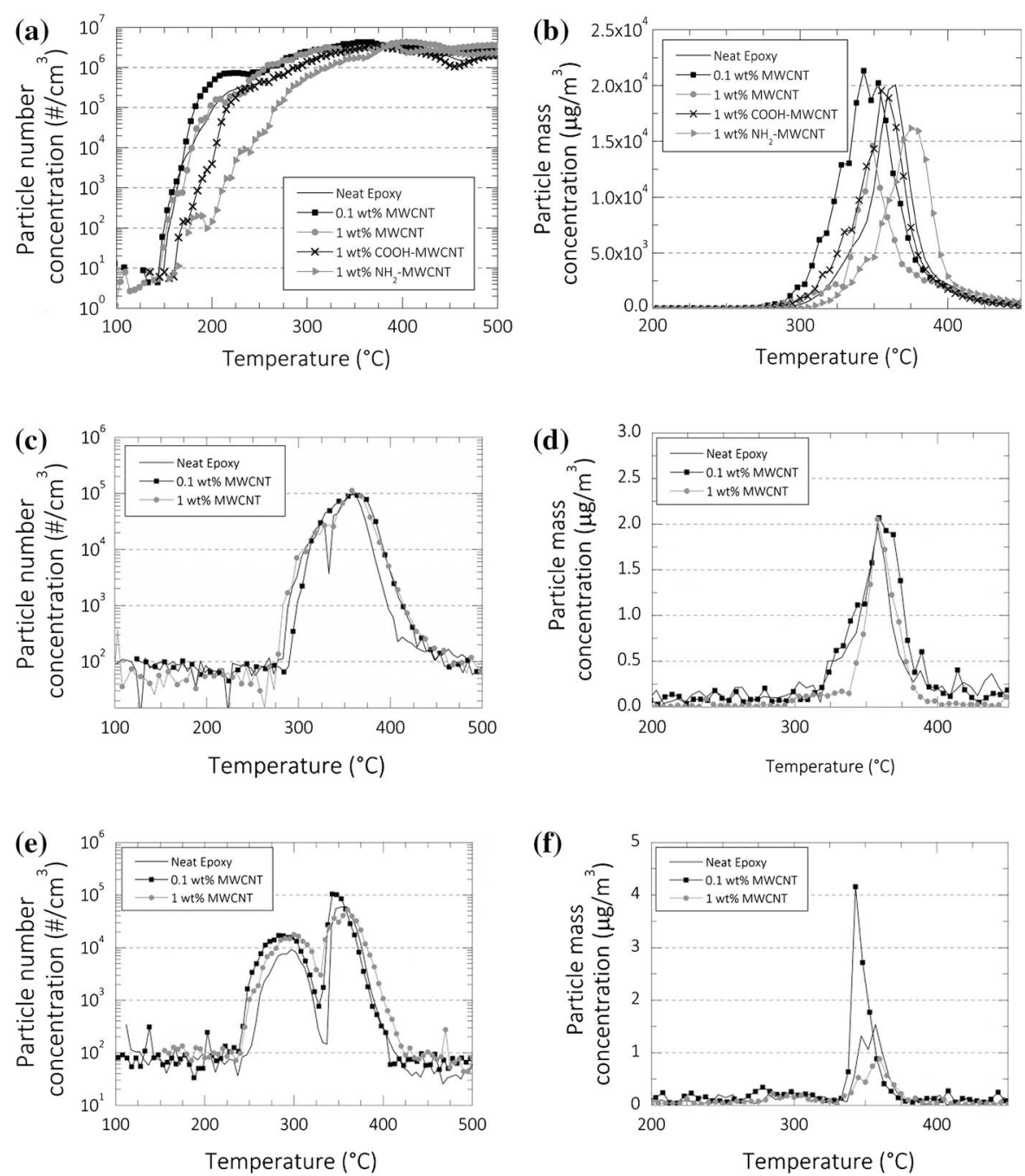
Electron microscope investigation

SEM images of the residues were recorded for all samples at both conditions, for decomposition under air and under nitrogen. An accumulation of MWCNTs on the surface was not observed for any of the samples as shown in the representative images in Fig. 5a for the neat epoxy, decomposed under air, and in Fig. $5 \mathrm{~b}$ for a COOH-MWCNT composite, also decomposed under air. On both samples, fiber-like structures, composed of degraded matrix material, are visible. Further, also partially porous structures were formed independent of the MWCNT concentration and configuration.

TEM samples were collected for thermal denudertreated exhaust from all samples in order to detect a possible MWCNT release. No free-standing
MWCNTs were found on the TEM grids, indicating that no or only very few MWCNTs were released during the decomposition process. In general, only a few particles were collected on the TEM grids and no MWCNTs were visible in those structures. Among the collected particles, also fibrous particles were detected, as shown in Fig. 5c, d. The two represented particles have different appearances, while in Fig. 5c no sign of sub-scale fibrous structures are visible, and a fibrous structure with a diameter of approximately $20 \mathrm{~nm}$ is visible in the lower part of the particle in Fig. 5d. Due to the similar absorbance as the carbon grid on the TEM grid, it can be assumed that the fibrous particles are composed of carbon and originate from the decomposing samples. The two presented particles have lengths of approximately 2 and $4 \mu \mathrm{m}$

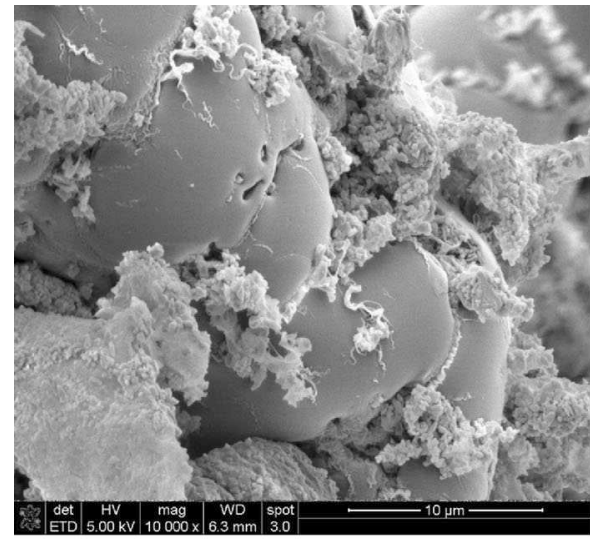

(a)

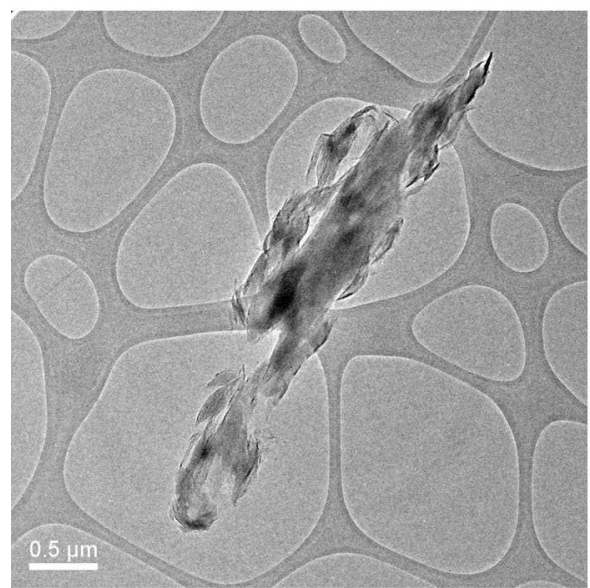

(c)

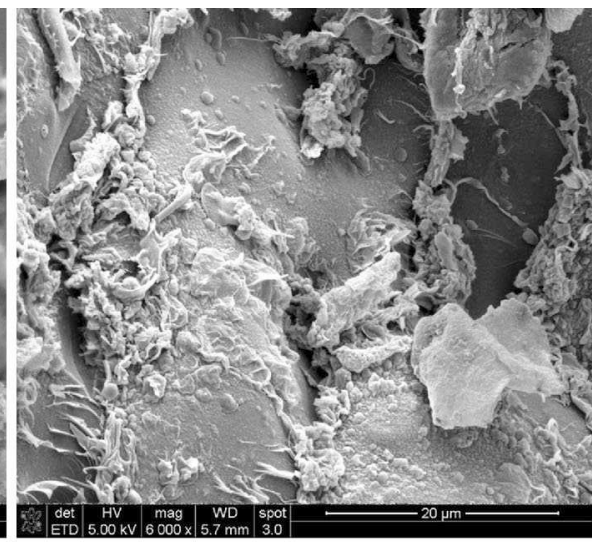

(b)

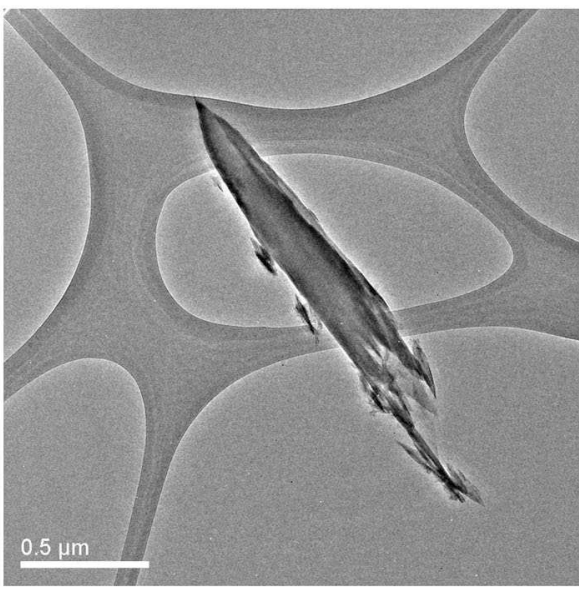

(d)

Fig. 5 a SEM image of a neat epoxy sample after decomposition under air; b SEM image of a COOH-MWCNT composite after decomposition under air; c, d TEM images of released fiber-like particles, released from decomposing samples 
and diameters of 0.2 and $0.7 \mu \mathrm{m}$, respectively. With length-to-diameter ratios larger than 3, they can be classified as fibers, small enough to penetrate into the lungs when inhaled, and thus they represent a potential hazard. Only few fibers were measured, an indication that the concentration was rather low.

\section{Discussion}

The results of the decomposition kinetics measurements allow several conclusions. It was shown that the addition of MWCNTs had an influence on the residue mass at the end of the TGA measurement. In contrast to the assumption that the longer duration of the experiment with low heating rates decreases the residue mass, and it was significantly higher for the composite samples. A possible explanation for this result could be that below the decomposition temperature, the added MWCNTs caused a time-consuming change of the epoxy chemistry. Further tests with differential scanning calorimetry (DSC) could give an explanation to this phenomenon.

The influence of the MWCNTs on the activation energy of the decomposition reaction has been described by several papers, and in general the activation energy increases when MWCNTs are added to polymers. This effect was measured for polyethylene (Shariati et al. 2012), polyethylene naphthalate (Kim et al. 2009), polyamide (Ribeiro et al. 2012), and polypropene (Seo and Park 2004). For the epoxy in this study and also in the study of Ciecierska et al. (2013), a lower activation energy was measured, accompanied by a shorter lifetime. The higher thermal conductivity as an explanation for this effect can be neglected since the concentration of MWCNTs in the epoxy had no influence on our results. It could be that the same effect that influenced the residue mass caused this irregularity.

For the characterization of the emissions during the decomposition experiments, different experimental configurations were needed to characterize the samples. On one side, the atmosphere either consisted of air or of nitrogen to simulate conditions where a fire causes a lack of oxygen and, on the other side, the influence of MWCNTs on the released particle number, especially for soot particles, was of interest.

The presence of oxygen clearly influenced the particle release behavior. At temperatures below $300{ }^{\circ} \mathrm{C}$, oxidation caused enhanced decomposition, followed by an emission of organic volatiles and soot particles. Due to this process, the thermal stability of epoxy was lower under air than under nitrogen. Further measurements with DSC are needed to measure the activation energy of this process and to determine its chemistry. Under both conditions, nitrogen or air, the particle mode and number are correlated with the measured mass concentration. This behavior changes after the main decomposition reaction, and the released mass decreases by two orders of magnitude, but the number of particles, consisting of volatiles, remains large. This shows a change in the decomposition mechanism, supported by the change of the activation energy for high conversion rates in Fig. 2b.

When the thermal denuder is used to remove the released organic volatiles, it is possible to distinguish between three decomposition regimes, the main decomposition reaction where soot particles are released, and the two slow decomposition reactions at temperatures below $300{ }^{\circ} \mathrm{C}$ and above $400{ }^{\circ} \mathrm{C}$. The addition of untreated MWCNTs to the epoxy had no substantial influence on the decomposition properties.

The SEM imaging revealed that MWCNTs were not exposed on the residue surface after the decomposition reaction. This behavior is different compared to burned CNT/polymer composites (Kashiwagi et al. 2002) and could have been caused by the low MWCNT fraction in the samples, by the high residue yield for the decomposition reaction, or by lower temperatures on the surface compared to burned samples. The epoxy further formed fiber-like structures on the surface of all samples, inclusive the neat epoxy. This behavior has already been reported for a CNT/polyamide nanocomposite (Christou and Stec 2014) and could be the origin of the fibrous particles, observed on the TEM grids in Fig. 5c, d.

Compared to the decomposition experiment of the CNT/ABS nanocomposite by Bouillard et al. (2013), no release of free-standing CNTs was detected for the decomposition of the epoxy nanocomposites. One difference between the investigated materials is that they belong to two different classes of polymers. ABS is a thermoplastic, i.e., it will melt and during the decomposition it was a fluid where the CNTs were able to diffuse to the surface and be released into the air. The small epoxy samples in this study did not change the shape during the decomposition process despite some shrinkage and thus were not liquid. This 
means that for the MWCNTs not close to the surface, it was not possible to diffuse through the char and be released. With the increasing temperature, the extent of oxidation and degradation of the polymer matrix and CNTs increases. At temperatures above $1000{ }^{\circ} \mathrm{C}$ as in incineration processes, the majority of CNTs are degraded and eventually oxidized (Mueller et al. 2013). In the present study, we did not detect released free-standing MWCNTs and therefore could not determine any degree of degradation.

\section{Conclusions}

A new experimental set-up was presented that is able to measure the particle release of a decomposing CNT/ polymer nanocomposite. The samples can be decomposed under nitrogen or under air, and the released particles can be post-treated with a thermal denuder in order to measure the particles without the released organic volatiles. Further, the collection of particles allows the determination of the shape and to measure a possible release of free-standing CNTs.

The results showed that the oxygen in the air caused the samples to decompose at lower temperatures compared to the decomposition under nitrogen. The usage of a thermal denuder for a post-treatment of the released particles did show that only $0.01 \mathrm{wt} \%$ of the released mass consisted of non-volatile particles. A release of free-standing MWCNTs was not observed, but micrometer-sized and respirable fibers at low concentrations were collected.

Acknowledgments This study was financed by the Swiss National Science Foundation (NFP 64), "Evaluation platform for safety and environment risks of carbon nanotube reinforced nanocomposites," 406440_131286.

\section{References}

Babrauskas V, Peacock RD (1992) Heat release rate: the single most important variable in fire hazard. Fire Saf $\mathbf{J}$ 18:255-272. doi:10.1016/0379-7112(92)90019-9

Bai JB, Allaoui A (2003) Effect of the length and the aggregate size of MWNTs on the improvement efficiency of the mechanical and electrical properties of nanocompositesexperimental investigation. Compos Part A 34:689-694. doi:10.1016/S1359-835X(03)00140-4

Bouillard J, R'Mili B, Moranviller D et al (2013) Nanosafety by design: risks from nanocomposite/nanowaste combustion. J Nanoparticle Res 15:1-11
Burtscher H, Baltensperger U, Bukowiecki N et al (2001) Separation of volatile and non-volatile aerosol fractions by thermodesorption: instrumental development and applications. J Aerosol Sci 32:427-442. doi:10.1016/S00218502(00)00089-6

Chatterjee S, Wang JW, Kuo WS et al (2012) Mechanical reinforcement and thermal conductivity in expanded graphene nanoplatelets reinforced epoxy composites. Chem Phys Lett 531:6-10. doi:10.1016/j.cplett.2012.02.006

Christou A, Stec AA (2014) Characterising the release of carbon nanotubes from burning CNT-polymer composites. In: Nanosafe 2014, Grenoble. http://www.nanosafe.org/home/ liblocal/docs/Nanosafe\%202014/Session\%206/06b-6\%20$\% 20$ Antonis\%20CHRISTOU.pdf.

Ciecierska E, Boczkowska A, Kurzydlowski KJ et al (2013) The effect of carbon nanotubes on epoxy matrix nanocomposites. J Therm Anal Calorim 111:1019-1024. doi:10.1007/ s10973-012-2506-0

Covaci A, Gerecke AC, Law RJ et al (2006) Hexabromocyclododecanes (HBCDs) in the environment and humans: a review. Environ Sci Technol 40:3679-3688

Dittrich B, Wartig K-A, Hofmann D et al (2013) Carbon black, multiwall carbon nanotubes, expanded graphite and functionalized graphene flame retarded polypropylene nanocomposites. Polym Adv Technol 24:916-926

Du J, Wang S, You H, Zhao X (2013) Understanding the toxicity of carbon nanotubes in the environment is crucial to the control of nanomaterials in producing and processing and the assessment of health risk for human: a review. Environ Toxicol Pharmacol 36:451-462. doi:10.1016/j.etap.2013. 05.007

Erdely A, Dahm M, Chen BT et al (2013) Carbon nanotube dosimetry: from workplace exposure assessment to inhalation toxicology. Part Fibre Toxicol. doi:10.1186/ 1743-8977-10-53

Fu S, Song P, Yang H et al (2010) Effects of carbon nanotubes and its functionalization on the thermal and flammability properties of polypropylene/wood flour composites. J Mater Sci 45:3520-3528

Ging J, Tejerina-Anton R, Ramakrishnan G, Nielsen M, Murphy K, Gorham JM, Nguyen T, Orlov A (2014) Development of a conceptual framework for evaluation of nanomaterials release from nanocomposites: environmental and toxicological implications. Sci Total Environ 473-474:9-19

Hollertz R, Chatterjee S, Gutmann H et al (2011) Improvement of toughness and electrical properties of epoxy composites with carbon nanotubes prepared by industrially relevant processes. Nanotechnology 22:125702. doi:10.1088/0957$4484 / 22 / 12 / 125702$

Huang H, Liu CH, Wu Y, Fan S (2005) Aligned carbon nanotube composite films for thermal management. Adv Mater 17:1652-1656. doi:10.1002/adma.200500467

Kaiser JP, Roesslein M, Buerki-Thurnherr T, Wick P (2011) Carbon nanotubes-curse or blessing. Curr Med Chem 18:2115-2128. doi:10.1007/s10101-010-0075-x

Kashiwagi T, Grulke E, Hilding J et al (2002) Thermal degradation and flammability properties of poly(propylene)/carbon nanotube composites. Macromol Rapid Commun 23:761-765 
Kashiwagi T, Grulke E, Hilding J et al (2004) Thermal and flammability properties of polypropylene/carbon nanotube nanocomposites. Polymer 45:4227-4239

Kashiwagi T, Du F, Winey KI et al (2005a) Flammability properties of polymer nanocomposites with single-walled carbon nanotubes: effects of nanotube dispersion and concentration. Polymer 46:471-481

Kashiwagi T, Du FM, Douglas JF et al (2005b) Nanoparticle networks reduce the flammability of polymer nanocomposites. Nat Mater 4:928-933

Kashiwagi T, Mu M, Winey K et al (2008) Relation between the viscoelastic and flammability properties of polymer nanocomposites. Polymer 49:4358-4368

Kim JY, Park HS, Kim SH (2009) Thermal decomposition behavior of carbon-nanotube-reinforced poly(ethylene 2,6naphthalate) nanocomposites. J Appl Polym Sci 113:2008-2017

Lu L, Yu H, Wang S, Zhang Y (2009) Thermal degradation behavior of styrene-butadiene-styrene tri-block copolymer/multiwalled carbon nanotubes composites. J Appl Polym Sci 112:524-531. doi:10.1002/app.29414

Ma P-C, Mo S-Y, Tang B-Z, Kim J-K (2010a) Dispersion, interfacial interaction and re-agglomeration of functionalized carbon nanotubes in epoxy composites. Carbon 48:1824-1834. doi:10.1016/j.carbon.2010.01.028

Ma PC, Siddiqui NA, Marom G, Kim JK (2010b) Dispersion and functionalization of carbon nanotubes for polymer-based nanocomposites: a review. Composites A 41:1345

Mouritz AP, Gibson AG (2006) Fire properties of polymer composite materials. Springer, New York

Mueller NC, Buha J, Wang J, Ulrich A, Nowack B (2013) Modeling the flows of engineered nanomaterials during waste handling. Environ Sci 15:251-259. doi:10.1039/ c2em30761h

Neises B, Steglich W (1978) Simple method for esterification of carboxylic-acids. Angew Chem Int Ed Engl 17:522-524

Nguyen T, Pellegrin B, Bernard C, Gu X, Gorham JM, Stutzman P, Stanley D, Shapiro A, Byrd E, Hettenhouser R, Chin J (2011) Fate of nanoparticles during life cycle of polymer nanocomposites. J Phys 304:12060

Nowack B, David RM, Fissan H et al (2013) Potential release scenarios for carbon nanotubes used in composites. Environ Int 59:1-11. doi:10.1016/j.envint.2013.04.003

Nyden MR, Harris RH, Kim YS et al (2010) Characterizing particle emissions from burning polymer nanocomposites. In: Technical proceedings of the 2010 NSTI nanotechnology conference expo, p 717-719

Ozawa T (1965) A new method of analyzing thermogravimetric data. Bull Chem Soc Jpn 38:1881-1886. doi:10.1246/bcsj. 38.1881

Pinto F, Costa P, Gulyurtlu I, Cabrita I (1999) Pyrolysis of plastic wastes. 1. Effect of plastic waste composition on product yield. J Anal Appl Pyrolysis 51:39-55. doi:10. 1016/S0165-2370(99)00007-8

Qu Z, Wang G (2012) A comparative study on the properties of the different amino-functionalized multiwall carbon nanotubes reinforced epoxy resin composites. J Appl Polym
Sci 124:403-411. doi:10.1002/app

Rahatekar SS, Zammarano M, Matko S et al (2010) Effect of carbon nanotubes and montmorillonite on the flammability of epoxy nanocomposites. Polym Degrad Stab 95:870-879. doi:10.1016/j.polymdegradstab.2010.01.003

Ribeiro B, Nohara L, Oishi S et al (2012) Nonoxidative thermal degradation kinetic of polyamide 6,6 reinforced with carbon nanotubes. J Thermoplast Compos Mater 26:1317-1331. doi:10.1177/0892705712439566

Schartel B, Pötschke P, Knoll U, Abdel-Goad M (2005) Fire behaviour of polyamide 6/multiwall carbon nanotube nanocomposites. Eur Polym J 41:1061-1070

Schlagenhauf L, Chu BTT, Buha J et al (2012) Release of carbon nanotubes from an epoxy-based nanocomposite during an abrasion process. Environ Sci Technol 46:7366-7372. doi:10.1021/es300320y

Seo M-K, Park S-J (2004) A kinetic study on the thermal degradation of multi-walled carbon nanotubes-reinforced poly(propylene) composites. Macromol Mater Eng 289:368-374. doi:10.1002/mame.200300303

Shariati J, Saadatabadi AR, Khorasheh F (2012) Thermal degradation behavior and kinetic analysis of ultra high molecular weight polyethylene based multi-walled carbon nanotube nanocomposites prepared via in-situ polymerization. J Macromol Sci Part A 49:749-757. doi:10.1080/ 10601325.2012.703520

Uddin N, Nyden MR, Davis RD (2011) Characterization of nanoparticle release from polymer nanocomposites due to fire. In: Nanotech 2011 conference and expo, p 1-4

Verdejo R, Barroso-Bujans F, Rodriguez-Perez MA et al (2008) Carbon nanotubes provide self-extinguishing grade to silicone-based foams. J Mater Chem 18:3933-3939

Vogt J (1985) Thermal analysis of epoxy-resins: identification of decomposition products. Thermochim Acta 85:411-414. doi:10.1016/0040-6031(85)85611-2

Wang J, Asbach C, Fissan H, Hülser T, Kuhlbusch TAJ, Thompson D, Pui DYH (2011) How can nanobiotechnology oversight advance science and industry: examples from environmental, health and safety studies of nanoparticles (nano-EHS). J Nanopart Res 13:1373-1387. doi:10.1007/s11051-011-0236-z

Willis J (2012) Proposal to amend Annex A to the Stockholm Convention to be discussed at the sixth meeting of the Conference of the Parties

Wu Q, Zhu W, Zhang C et al (2010) Study of fire retardant behavior of carbon nanotube membranes and carbon nanofiber paper in carbon fiber reinforced epoxy composites. Carbon 48:1799-1806

Zammarano M, Krämer RH, Harris R et al (2008) Flammability reduction of flexible polyurethane foams via carbon nanofiber network formation. Polym Adv Technol 19:588-595. doi:10.1002/pat

Zybex technologies (2014) Safety Data Sheet ZNT-boost (Solid). Retrieved from http://www.zyvextech.com/assets/ pdf/ZNT-bOOST-SOLID-Resin-Linear-Polymer-200325 14-3.pdf 